\title{
A Two Years Retrospective Study on Prevalence of Hospital Acquired Surgical Site Infections Among Patients Admitted in Wolaita Soddo Teaching and Referral Hospital
}

\author{
Wogayehu Abera ${ }^{1} \quad$ Bereket Gebremeskel $^{1} \quad$ Getahun Dendir $^{1} \quad$ Naol Gorde $^{1}$ \\ Ashebir Debalike $^{1} \quad$ Ephrem Nigussie $^{2} \quad$ Tsegaye Demeke $^{1}$ \\ 1.Department of Anesthesia,School of Medicine,Wolaita Sodo University, Wolaita Soddo, Ethiopia \\ 2.Department of Anesthesia,School of Medicine,Arsi University, Addis Ababa, Ethiopia
}

\begin{abstract}
Background: Surgical site infections are the second most common type of adverse events occurring in hospitalized patients. A surgical wound infection occurs when micro -organisms from the skin or the environment enter the incision that the surgeon makes through the skin in order to carry out the operation.

Objectives: To determine the prevalence of surgical site infections among patients admitted to WSUTR Hospital, southern Ethiopia.

Method and materials: A two years retrospective cross-sectional study was conducted in WSUTRH, 2015. The study was conducted on secondary data from September 2012 to August 2014 using patient cards.

Result

334 patient cards were included in our study by proportion 183 were from Obs/Gyn and 151 of surgical cases. From this $10(3 \%), 6(1.8 \%)$ and $5(1.5 \%)$ of patients who undergo surgery are diagnosed as having postoperative wound infection on date of 3-4 day, $5^{\text {th }}$ or more days post operative period in the hospital and at home after discharge respectively. Most patients develop infection after 3or more days post operative.

Conclusion

Surgical site infection (SSI) is an infection that occurs at the incised site. Surgical site infection (SSI) is one of the most common postoperative complications and occurs in at least five per cent of all patients undergoing surgery.

Recommendation:

Put into practice that provision of antibiotics before surgery since preoperative prophylactic antibiotics prevents from postoperative infections as well as surgical sight infection.
\end{abstract}

DOI: $10.7176 / \mathrm{JBAH} / 9-4-01$

\subsection{BACKGROUND}

Surgical site infection (SSI) is one of the most common postoperative complications and occurs in at least five per cent of all patients undergoing surgery (1).

The rate of SSI is significantly higher after open abdominal surgery which can carry an SSI risk of up to $40 \%$ depending on level of contamination (2).

SSI is associated with considerable morbidity and it has been reported that over one-third of postoperative deaths are related, at least in part, to SSI (3).

It must be appreciated, however, that the diagnosis covers a wide spectrum of clinical conditions ranging from a relatively trivial wound discharge with no other complications to a life-threatening condition. Other clinical outcomes of SSI include poor scars that are cosmetically unacceptable, such as those that are hypertrophy or keloid, persistent pain and itching and a significant impact on emotional wellbeing (4).

SSI can double the length of time a patient stays in hospital and thereby increase the costs of health care. Additional costs attributable to SSI have been reported depending on the type of surgery and the severity of the infection (5).

The main additional costs are related to re-operation, extra nursing care and interventions, and drug treatment costs. The indirect costs, due to loss of productivity, patient dissatisfaction and litigation, and reduced quality of life, have been studied less extensively.The use of antibiotic prophylaxis before surgery has evolved greatly in the last 30 years. Improvements in the timing of initial administration, the appropriate choice of antibiotic agents, and shorter durations of administration have more clearly defined the value of this technique in reducing postoperative surgical site infections. The choice of parenteral prophylactic antibiotic agents and the timing and route of administration have become standardized on the basis of well-planned prospective clinical studies. In elective, clean surgical procedures using a foreign body and in clean-contaminated procedures, it is generally recommended that anesthesia personnel administer intravenously a single dose of cephalosporin (e.g. cefazolin) just before incision. Additional doses are generally recommended only when the operation lasts longer than 2 to 3 hours. Controversial areas include the routine use of antibiotic prophylaxis in clean surgical procedures, such as hernia repair or breast surgery (6).

Recent national guidelines concerning the prevention and treatment of SSI have been issued by the National 
Institute for Health and Clinical excellence (NICE) (7).

These recommendations are based on systematic reviews of best available evidence, or when minimal evidence is available the guideline development group's opinion of what constitutes good practice. Intra-operative guidance includes the role of hand decontamination, sterile gowns and drapes and antiseptic skin preparation.Most surgeons use both antibiotics and mechanical cleansing for preoperative preparation before elective colon resection (8).

Three separate regimens of oral agents combine neomycin with erythromycin base, metronidazole, or tetracycline. Recent improvements in antibiotic prophylaxis, including the timing of initial administration, appropriate choice of antibiotic agents, and shortening the duration of administration have established the value of this technique in many clinical surgical settings. A single dose systemic regimen of an appropriately chosen cephalosporin given during the immediate preoperative period is safe and the indicated practice in cleancontaminated procedures (other than elective colon resection) and in clean operative procedures associated with the use of foreign bodies (mesh, vascular grafts)(9).

\subsection{Statement of the problem}

Hospital-acquired infection is a major health problem throughout the world and is the most common complication affecting hospitalized patients. It has been associated with an increased in morbidity, mortality and excess healthcare cost that has huge economic impact (10).

The risk of acquiring hospital infection on hospitalized patients in relation to surgery is high, since about $77 \%$ of death of patients with Nosocomial infection was reported to be related with post-operative infection [11].

The number of surgical patients in developing countries is also increasing but surgical care given to the patients is poor. If we look for reasons of hospital admissions of children in sub-Saharan Africa, surgical condition are responsible for approximately $6-12 \%$ of all pediatric admission but due to poor surgical care, there is a significant number of death and case of disability, because surgical care is not considered as an essential component of most child health care programs. In Ethiopia, previous studies indicated high prevalence of hospital acquired infections. A rate of $47 \%$ and $59 \%$ for SSI; and $15 \%$ and $26 \%$ for UTI were reported from Addis Ababa (12).

\subsection{Literature Review}

Postoperative surgical site infections remain a major source of illness and a less frequent cause of death in the surgical patient. These infections number approximately 500,000 per year, among an estimated 27 million surgical procedures and account for approximately one quarter of the estimated 2 million Nosocomial infections in the United States each year. Infections result in longer hospitalization and higher costs. (14)

Surgical site infection (SSI) is an infection that occurs at the incised site. It can be classified as superficial incision, deep incision and organ/space surgical site infection. The superficial incision involves the skin and subcutaneous tissue of the incision, and usually occurs within 30 days after the operative procedure. Deep incision SSI involves deep soft tissues such as soft tissue of the chest, soft tissue of the leg, and facial and muscle layers. The infection is considered as hospital-acquired SSI if it occurs within 30 days of the operative procedure if no implant is left in place and within a year if implant is in place and the infection appears to be related to the operative procedure (15).

There is a generally accepted classification for wound infections (SSI) devised by the National Academy of Sciences and National Research council. The classification is based on the degree of intra-operative microbial contamination and infection. According to the classification, operations can be categorized as class-I or clean (i.e. an uninfected operative wound in which no inflammation is encountered), class-II operation or clean-contaminated (i.e. an operative wound in which the respiratory, alimentary, genital, or urinary tracts are entered under controlled conditions and without unusual contamination), class-III operation or contaminated (i.e. open, fresh, accidental wounds),and (i.e. old traumatic wounds with retained devitalized tissue and those that involve existing clinical infection or perforated viscera)(16)

The possible mode of transmission for hospital acquired infection are either cross-infection due to indirect spread of the pathogens via patients contact stay or autoinfection from an endogenous flora found in the patient. For example surgical site infection can be caused by an endogenous flora that translocations to a normally sterile site or when the sterile peritoneal cavity is contaminated by spillage from the gastrointestinal tract; and by an exogenous source of microbial contamination that comes from the surgical team, surgical instrument and the theatre environment. The type of surgical procedure and duration of the operation also contribute to the occurrence of the infection. Further-more, aseptic procedures were not followed strictly by the majority of the nurses and physicians in several practice areas and is found to be significant for the transmission of the infection (16)

All patients undergoing a surgical procedure are placed at some risk of infections. These risk factors are: the number and virulence of the contaminating micro -organisms, the operative and environmental factors like the surgeon' skill and cleanness of the theatre, the nature of the operation like its classification such as clean, clean-- 
9 -contaminated, and contaminated, Patients' age, smoking, obesity, malnutrition and immunosuppressant therapy, Local factors such as presence of wound drains, hair removal or previous irradiation of site (17).

The diagnosis and identification of hospital-acquired infection involves interpretation of clinical and laboratory findings. Clinically, a patient is assessed based on clinical sign and symptoms developed due to the infection. A patient with a superficial incision site infection will have pain, tenderness, redness, localized swelling and purulent drainage from the incision. But if the infection is at a deep incision, the patient will develop fever $\left(>38^{\circ} \mathrm{C}\right)$, localized pain or tenderness and purulent drainage from the incision. The treatment of post-operative wound infection requires drainage or surgical excision of the infected or necrotic material and antibiotic therapy(18).

The postoperative indications for antibiotic therapy are classified as either empiric treatment or infection directed treatment. The empiric treatment is given to patients for post-operative fever without a specific localized source of infection and infection-directed treatment is considered when the antibiotics therapy is administered for a specific clinically localized source of infection. However, receiving empiric antibiotics in the postoperative period had a greater risk of acquiring antibiotic-resistant infection (19).

The antimicrobial drugs most commonly used for treatment of post-operative wound infections are betalactam antibiotics, amino glycosides, fluoroquinolones, Trimethoprimsulfamethoxazole, Chloramphenicol, Polymyxin and Colistin (20).

On the other hand the antibiotics mostly used in the prophylaxis during surgery are first, second and third generation cephalosporin's, penicillin, fluoroquinolones, glycopeptides, and amino glycosides(21).

\subsection{Significance of the study}

This study provides information for nurses that help as a useful guide for control of hospital-acquired post OP wound infection in WSTRH.

\subsection{General objective}

To determine the prevalence, create awareness on cause and prevention of hospital acquired surgical site Infections among patients admitted to WSTR Hospital from September 2012 to August 2014.

\subsection{Specific Objectives}

$>$ To determine the prevalence of surgical site infections among patients admitted to WSTRH.

$>$ To create awareness on causes of surgical Site infections among nurses working on WSTRH.

$>$ To sagest effective ways on how to prevent surgical Site infections in WSTRH.

\subsection{Study period}

The study was conducted on secondary data from September 2012 to August 2014 in Wolaita Sodo University Teaching Hospital.

\subsection{Study Area}

Wolaita Soddo University Teaching Hospital (WSUTH) is found in South Nations Nationalities and People Region States (SNNPRS), Ethiopia. The teaching hospital is located in Sodo town of Wolaita Zone, SNNPRS which is $380 \mathrm{~km}$ away from the national capital Addis Ababa and $170 \mathrm{~km}$ far from the regional capital Hawassa. The teaching hospital was established in 1928 and serving people in catchment area of 2 million people including neighboring Dawuro zone, Gamo gofa zone and Kambata Tambaro zone. With the total capacity of about 170 inpatient beds in four major departments and other units (WSUTH Annual report, 2015). Especially on patients admitted to surgical and obs/ gyn wards.

\section{Health professionals and supportive staffs of WSUTRH}

\begin{tabular}{|l|l|l|}
\hline $\mathbf{S . N}$ & Type of Professional & Number \\
\hline $\mathbf{5}$ & Specialists & $\mathbf{0 9}$ \\
\hline $\mathbf{6}$ & General medical practitioner & $\mathbf{3 5}$ \\
\hline $\mathbf{7}$ & Health officer & $\mathbf{1 0}$ \\
\hline $\mathbf{9}$ & Nurses (All type) & $\mathbf{1 3 7}$ \\
\hline $\mathbf{1 2}$ & Laboratory technologists \& technicians & $\mathbf{2 0}$ \\
\hline $\mathbf{1 4}$ & Pharmacist \& technicians & $\mathbf{2 0}$ \\
\hline $\mathbf{1 6}$ & Anesthetist & $\mathbf{1 7}$ \\
\hline $\mathbf{1 7}$ & Environmental health technicians & $\mathbf{0 3}$ \\
\hline $\mathbf{1 8}$ & X-ray (All type) & $\mathbf{0 4}$ \\
\hline $\mathbf{1 9}$ & Other technical staffs \& supportive staff & $\mathbf{1 5 5}$ \\
\hline \hline TOTAL & $\mathbf{4 1 0}$ \\
\hline
\end{tabular}




\subsection{Study Design}

Two years retrospective cross sectional study was employed on all patients who were admitted in Gyn/Obs and surgery wards after major surgery.

\subsection{Population}

4.4.1. Source population: - All patients who were admitted to surgical, OB and GYN wards of WSTRH from September 2012 to August 2014.

4.4.2. Study population: -The study population was the population who were operated in GYN/OB and surgical wards of WSTRH from September 2012 to August 2014.

\subsection{INCLUSSIVEAND EXCLUSSIVE CRITERIA}

\subsubsection{Inclusion criteria}

Charts/cards which answers $>90 \%$ of the questionnaires were included.

\subsubsection{Exclusion criteria}

Those cards /charts which answers $<90 \%$ of the questionnaires were excluded.

\subsection{Sample size and sampling Techniques}

\subsubsection{SAMPLING TECHNIQUE}

$>$ A retrospective review of records of all patients operated from GYN/OBS and surgical cases from September 2012 to August 2014.

> Sample was determined from all patients who undergo surgery during study period by using sample size calculation formula and scientific calculator.

$>$ A systemic random sampling was used to asses patients from the $\mathrm{k}^{\text {th }}$ value

$\mathrm{N} / \mathrm{n}=2595 / 384=6.77$, approximately every 7 patient interval was selected and the first patient was selected by lottery method after patient arranged in raw at WSTR hospital.

\subsubsection{Sample Size Determination}

The sampling size is determined by the formula

$$
\mathrm{n}=\frac{(\mathrm{z} 1-\mathrm{a} / 2)^{2} \mathrm{p}(1-\mathrm{p})}{\mathrm{D}^{2}}
$$

Where: $\mathrm{n}=$ the minimum sample size

$\mathrm{p}=$ an estimate of prevalence rate of SSI

$\mathrm{Z}=$ Value of standard normal variable

$\mathrm{n}=\underline{(1.96)^{2}(0.5)(0.5)}=384$ cards at $95 \%$ confidence level $(1.96)$

$\mathrm{N}=2595$

$$
(0.05)^{2}
$$

$\mathrm{D}=$ margin of error $(5 \%)$

$\mathrm{d}=$ is the margin of sampling error tolerated $\mathrm{za}^{2}$ is standard normal variable at $1.2 \%$ confidence level and $\infty$ is $5 \%$

$$
\mathrm{Z} \infty 2=1.96
$$

Then using correction formula for finite population since source population is less than 10,000 .

Where $\mathrm{n}=$ the minimum sample size $=384$

$\mathrm{Nf}=\mathrm{n} / 1+\mathrm{n} / \mathrm{N}=384 / 1+(384 / 2595)=334$

$\mathrm{N}=$ Total no admitted patient $=2595$

nf $=$ Final sample study $=\mathbf{3 3 4}$

\subsection{Study variables}

\subsubsection{Dependent variable}

$>$ Surgical site infections

$>$ Ward

$>$ Patient condition.

$>$ Duration of operation

4.6.2 Independent variables

$$
\begin{array}{ll}
* & \text { Age } \\
* & \text { Sex } \\
* & \text { Address }
\end{array}
$$

\subsection{Data Collection Technique}

The study was retrospective chart review of the patient admitted at OBS/GYN and surgical wards of WSTRH. Data was collected by medical students who are trained for five hours. 


\subsection{Data processing and Analysis}

The data was collected and tallied manually on tally sheet then the data was analyzed by using scientific calculator. Their statically significance was assessed with the dependent variables. Finally using international and national data the result was compared, discussed and Conclusion and recommendation was forwarded based on the result of the research.

\subsection{Data Quality Assurance}

Pretest was done before data collection; supervision was carried out throughout the whole data collection period by trained and assigned supervisors. Throughout the data collection the principal investigator checked the completeness, ambiguous suspicions; impossible variables filled and was checked on the spot and corrected accordingly.

\subsection{Ethical Consideration}

After approval of proposal from department of anesthesia, a letter of support and permission was obtained from anesthesia department given to WSUTRH. The information obtained should be used only for the study purpose. After completion of data collection, medical records were returned back to their original place properly.

\section{11. Limitations of the study}

-Some of patient's cards were lost or incomplete and time constraints of the study.

\subsection{Plan for dissemination of findings}

The result of the study were disseminated to WSUTRH College of health science, Department of Anesthesia, WSUTRH and Zonal health offices,

\section{OPERATIONAL DEFINITION}

Anesthesia: relief and prevention of pain during and following Surgical, obstetric, therapeutic, and diagnostic procedures.

General Anesthesia: is most often produced by using a combination of drugs to induce a state of reversible unconsciousness.

Regional anesthesia: is type of anesthesia administered at site of action to undergo nerve blockage using local anesthetic drug.

Surgery: is a branch of medicine that is concerned with the treatment of injuries, disease and other disorders by manual and instrumental means.

Emergency surgery: is surgery done in certain indications which need immediate interventions.

Elective surgery: is surgery done before on set (appearance) of any complication that might constitute Urgent indication.

\section{RESULT}

Two thousand five hundred ninety five patients admitted to undergo surgery for Obs/Gyn and surgical cases of WSTRH during last 2years from September 2012 to August 2014, of which 1419(54.7\%) are Obs/Gyn and of $1176,764(29.4 \%)$ male and 412(15.9\%) female are surgical case. From the total of 2595 cases, 334 were included in our study by proportion 183 were from Obs/Gyn and 151 of surgical cases. Of them 18(5.3\%) were less than 15 and 316(94.7\%) greater than 15 years old; whereas $156(46.7 \%)$ rural and $176(53.3 \%)$ urban.

TABLE 1: THE WARD PATIENTS ADMITTED FOR THOSE UNDERWENT SURGERY IN WSUTRH FROM SEPT 2012-AUG. 2014

\begin{tabular}{|l|l|l|l|l|}
\hline \multirow{2}{*}{ Ward } & \multicolumn{2}{|l|}{ Frequency } & Percentage \\
\cline { 2 - 5 } & Sex & Sex & \multicolumn{2}{l|}{} \\
\cline { 2 - 5 } & Male & Female & Male & Female \\
\hline Surgical & 764 & 412 & 29.4 & 15.9 \\
\hline Obs/Gyn & O & 1419 & 0 & 54.7 \\
\hline
\end{tabular}

From the total of 2595 cases, 1176(45.3\%) were surgical and 1419(54.7\%) were obstetric and gynecologic cases. From this table we can appreciate that majority of cases from Obs/Gyn than surgical. 
TABLE 2: PATIENT IDENTIFICATION BY AGE CATEGORY FOR THOSE UNDERWENT SURGERY IN WSUTRH FROM SEPTEMBER 2012 TO AUGUST 2014.

\begin{tabular}{|l|l|l|l|l|}
\hline \multirow{2}{*}{ Age } & \multicolumn{2}{c|}{ Frequency } & \multicolumn{2}{c|}{ Percentage } \\
\cline { 2 - 6 } & \multicolumn{2}{c|}{ Sex } & \multicolumn{2}{c|}{ Sex } \\
\cline { 2 - 6 } & Male & Female & Male & 0.3 \\
\hline $0-4$ & 2 & 1 & 0.6 & 1.7 \\
\hline $5-14$ & 9 & 6 & 2.7 & 68.7 \\
\hline$\geq 15$ & 87 & 229 & 26 & Female \\
\hline
\end{tabular}

From surgery in our study period, $3(0.9 \%)$ were $0-4$ years, $15(4.4 \%) 5-14$ years and the rest $316(97.7 \%)$ were 15 or above 15 years old.

TABLE 3: PATIENT IDENTIFICATION BY DISTINATION FOR THOSE UNDERWENT SURGERY IN WSUTH FROM SEPTEMBER 2012 TO AUGUST 2014

\begin{tabular}{|l|l|l|l|l|}
\hline \multirow{2}{*}{ Address } & \multicolumn{2}{|l|}{} \\
\cline { 2 - 5 } & Srequency & Percentage & \multicolumn{2}{|l|}{} \\
\cline { 2 - 5 } & Sex & Female & Sex & Male \\
\hline Rural & 50 & 106 & 15 & 31.7 \\
\hline Urban & 52 & 126 & 15.6 & 37.7 \\
\hline
\end{tabular}

Table 3 reviles that surgical cases operated in the hospital of total, 50\% and more were from urban than rural. This may be due to its access and improved knowledge towards medical care.

TABLE4: DIAGNOSIS OF ADMISSION BEFORE SURGERY FOR THOSE UNDERWENT SURGERY IN WSUTRH FROM SEPT 2012-AUG. 2014

\begin{tabular}{|l|l|l|}
\hline Diagnosis of admission before surgery & \multicolumn{1}{|c|}{ In Number } & By Percent (\%) \\
\hline Obstetric & 128 & 38.3 \\
\hline Gynecologic & 52 & 15.6 \\
\hline Surgery & 146 & 43.7 \\
\hline Other medical cases & 8 & 2.4 \\
\hline
\end{tabular}

Of 334 cases presented in table four below, 128(38.3\%) were obstetric, 52(15.6) were gynecologic, $146(43.7 \%)$ surgery whereas $8(2.4 \%)$ were admitted for other medical cases but found to be diagnosed as surgical cases and undergone surgery.

TABLE 5: ANTIBIOTIC PROPHYLAXIS GIVEN FOR PATIENT'S FOR THOSE UNDERWENT SURGERY IN WSUTRH FROM SEPT 2012- AUG. 2014

\begin{tabular}{|l|l|l|l|l|}
\hline \multirow{2}{*}{ Antibiotic prophylaxis given } & Yes & No & \\
\cline { 2 - 5 } In Number & Male & Female & Male & Female \\
\hline By Percent (\%) & 68 & 148 & 35 & 83 \\
\hline
\end{tabular}

However, table five above shows $118(35.3 \%)$ patients who were not given prophylaxis antibiotic; this may be highly contributed for SSI. 


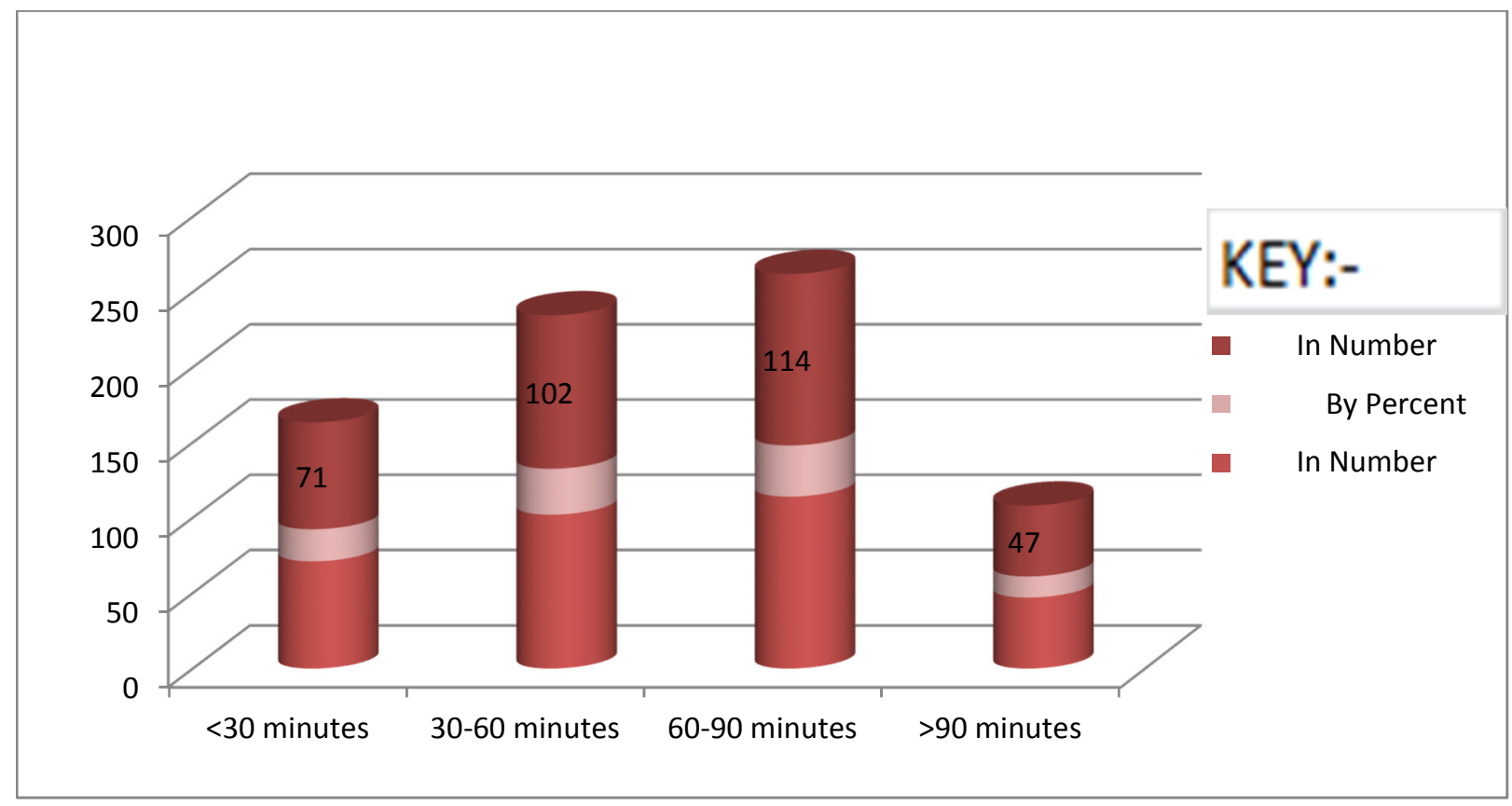

FIGURE 1: THE DURATION ANESTHESIA TAKEN FOR PATIENTS UNDERWENT SUGERY AT WSUTRH FROM SEPT 2012- AUG. 2014

Figure one above demonstrate more than $14 \%$ of patients their duration of anesthesia was longer than 90 minutes. Prolonged anesthesia time for prolonged surgical procedure increases the risk of acquiring surgical site infection due to prolonged exposure to external environment.

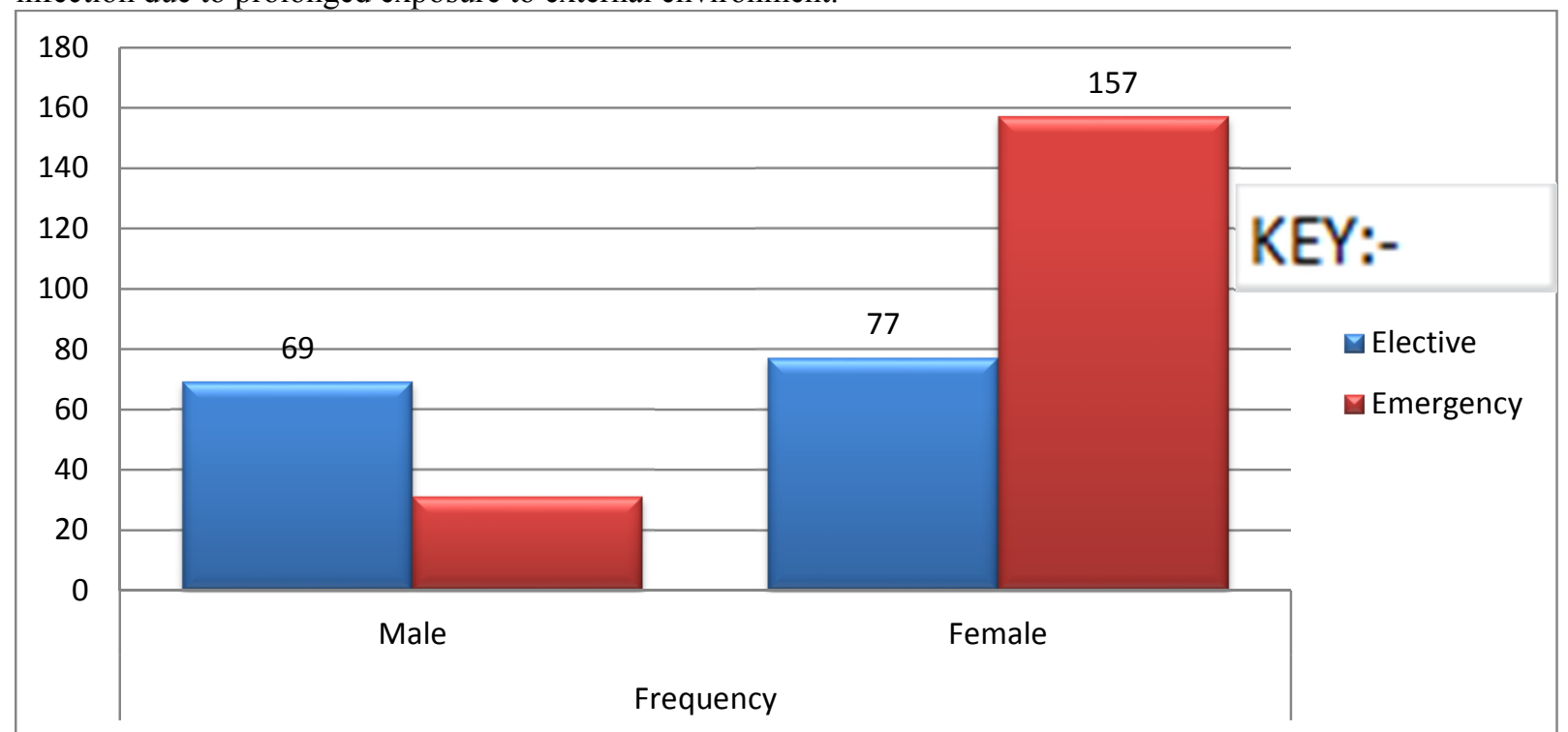

FIGURE 2: TYPE OF SURGERY DONE TO THE PATIENT FOR THOSE UNDERWENT SURGERY IN WSUTRH FROM SEPT. 2012- AUG. 2014

In the figure 2 shown above, from 334 patients 146(43.7\%) were elective and $188(56.3 \%)$ were emergency cases. The increment in emergency cases may be due to emergency obstetric cases like cesarean section delivery and uterine rupture operations.

TABLE 6: TYPE OF ANESTHESIA GIVEN TO THE PATIENT FOR THOSE UNDERWENT SURGERY IN WSUTRH FROM SEPT. 2012- AUG. 2014

\begin{tabular}{|l|l|l|}
\hline Type of anesthesia given & In number & By percent \\
\hline General & 100 & 30 \\
\hline Regional & 234 & 70 \\
\hline
\end{tabular}

In Table 6; Patients for whom surgery done under general anesthesia were less than regional anesthesia i.e. $100(30 \%)$ and $234(70 \%)$ respectively. 
TABLE 7: DURATION OF POSTOPERATIVE WOUND INFECTION DIAGNOSED FOR THOSE UNDERWENT SURGERY IN WSUTRH FROM SEPT 2012- AUG. 2014

\begin{tabular}{|l|l|l|}
\hline The time of postoperative wound infection diagnosed & In number & By percent \\
\hline Within two days post surgery & 0 & 0 \\
\hline 3-4 day post operation & 10 & 3 \\
\hline $5^{\text {th }}$ and more days after surgery & 6 & 1.8 \\
\hline At home after discharge & 5 & 1.5 \\
\hline
\end{tabular}

$10(3 \%), 6(1.8 \%)$ and $5(1.5 \%)$ of =patients are diagnosed as having postoperative wound infection on date of 3-4 day, $5^{\text {th }}$ or more days post operative period in the hospital and at home after discharge respectively as shown above in table 7.

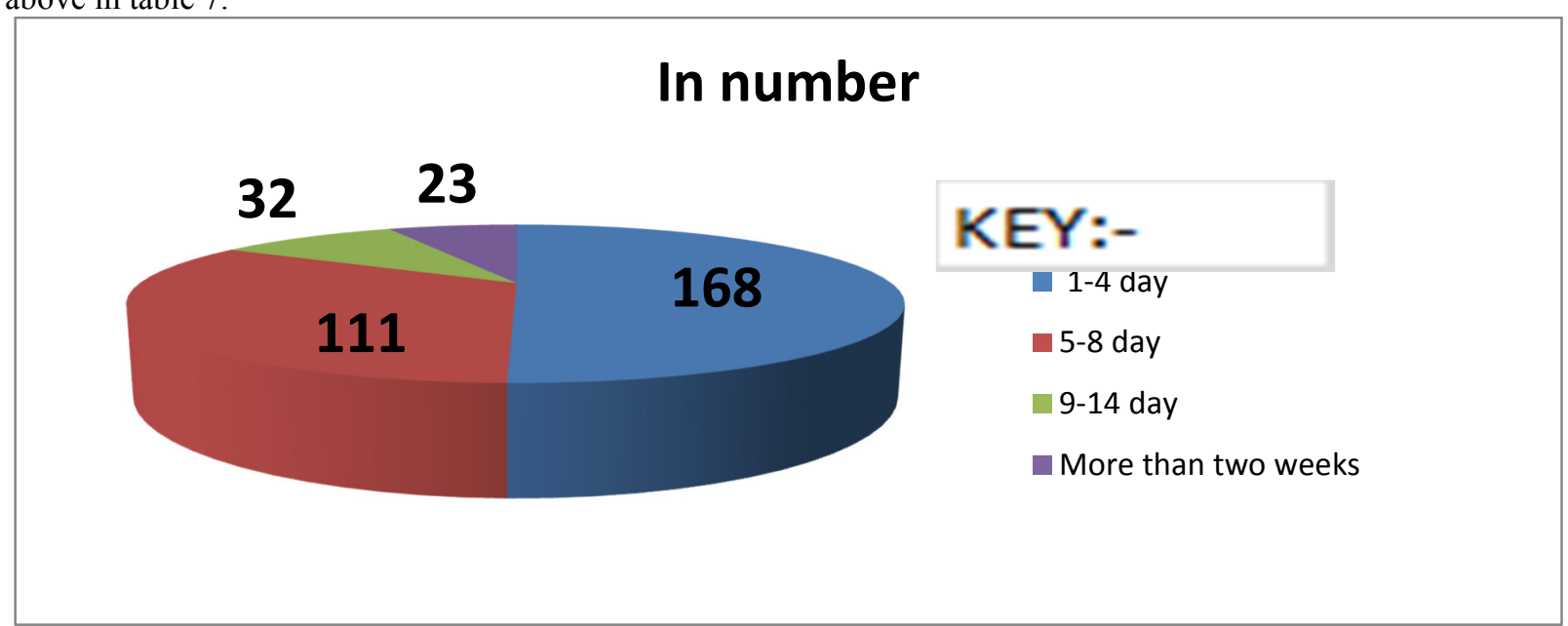

FIGURE 3: DURATION OF HOSPITAL STAYS AFTER SURGERY TO THE PATIENT FOR THOSE UNDERWENT SURGERY IN WSUTRH FROM SEPT. 2012-AUG. 2014

Figure three above suggests that about $50 \%$ of cases stay at hospital for 5 or more than 5 days. Prolonged stay at hospital has direct correlation with surgical site infection. Therefore, decreasing hospital stay is one of the major tasks that require special attention for the reduction of risk of developing SSI.

\section{DISCUSSION}

Postoperative surgical site infections remain a major source of illness and a less frequent cause of death in the surgical patient. These infections number approximately 500,000 per year, among an estimated 27 million surgical procedures and account for approximately one quarter of the estimated 2 million Nosocomial infections in the United States each year. Infections result in longer hospitalization and higher costs. (14)

In our research, the proportion of male and female is about $29.4 \%$ and $70.6 \%$ this is by far differ from national male female ratio the reason behind this discrepancy is; more than $50 \%$ of study population and all of them from Obs/Gyn ward were females and half of surgery cases too. Age category for those undertake operation from 334 who undergo surgery in our study period, 3(0.9\%) were 0-4 years, 15(4.4\%) 5-14 years and the rest 316(97.7\%) were 15 or above 15 years old. It expresses that the risk of being operated or any other injury is obviously increases with age. 50\% and more were from urban compared to rural. This may be due to nearby access and improved awareness towards medical care.

From our result above More than $14 \%$ of patients the duration of anesthesia were longer than 90 minutes. Since prolonged anesthesia time is for prolonged surgical procedure, the type of surgical procedure and duration of the operation also contribute to the occurrence of the infection. (10)

From findings in result section for diagnosis of admission before surgery, 128(38.3\%) were obstetric, 52(15.6) were gynecologic, $146(43.7 \%)$ surgery whereas $8(2.4 \%)$ were admitted for other medical cases but found to be diagnosed as surgical cases and undergone surgery. Clearly, Obs/Gyn especially obstetric operation outweighs more than surgery of other causes.

$118(35.3 \%)$ patients who undergo sugary during our study period were not given prophylaxis antibiotic; this increases prevalence of SSI compared to the research finding in United States $(1.8 \%)$.

The result in this research shows, 146(43.7\%) were elective and 188(56.3\%) were emergency cases. The increment in emergency cases may be due to emergency obstetric cases like cesarean section delivery and uterine rupture operations.

In our study, $10(3 \%), 6(1.8 \%)$ and $5(1.5 \%)$ patients are diagnosed as having postoperative wound infection on date of 3-4 day, $5^{\text {th }}$ or more days post operative period in the hospital and at home after discharge respectively 
which is more prevalent than the finding in above research of US $(1.8 \%)$.

Surgical site infection (SSI) is an infection that occurs at the incised site. Surgical site infection (SSI) is one of the most common postoperative complications and occurs in at least five per cent of all patients undergoing surgery (1).

We postulate that this prevalence in the present study is due to a combination of factors including the practice of antibiotic prophylaxis in the Hospital, not following aseptic procedures strictly and factors related to the patient. However; differences in methodologies and patient population do not allow stringent comparison of prevalence between different surveys, and meaningful comparison of infection rates is required an adjustment of both the intrinsic and extrinsic risk factors of the infection.

In our study, the average hospital stay was 5 days and more for $50 \%$ of study population and this also contributes for the prevalence of SSI.

\section{CONCLUSION AND RECOMMENDATION}

\section{1 conclusions}

Surgical site infection (SSI) is one of the most common postoperative complications and occurs in at least five per cent of all patients undergoing surgery. It is associated with considerable morbidity and has been reported as cause for over one-third of postoperative deaths. Since researches are the back bones for health service quality improvement, health institutions should use such wonderful opportunity for self monitoring and evaluation.

This prevalence in the present study is due to a combination of factors including the practice of antibiotic prophylaxis in the Hospital, not following aseptic procedures strictly and factors related to the patient. We should follow the recent national guidelines concerning the prevention and treatment of SSI for effective prevention and management of SSI.

\section{2 recommendations}

* Proper documentation at hospital level with standard stapes diagnosis to measure and work for reversing identified gap.

* Institutional arrangement to ease trend for researchers in the hospital should be considered.

* Using data for self examination and setting goals to be done at institution level since researches are spinal column of health service improvement.

* The hospital should develop experience of using researchers' findings to improve its own on service.

* The hospital should develop experience of preserving research papers done at hospital for self evaluation and reference for other researchers.

* Put into practice that provision of antibiotics before surgery since preoperative prophylactic antibiotics prevents from postoperative infections as well as surgical sight infection.

\section{Annexes}

\section{Annex -I REFERENCES}

1. Smyth ET, McIlvenny G, Enstone JE, Emmerson AM, Humphreys H, Fitzpatrick F, Davies E, Newcombe RG, Spencer RC: Four Country Healthcare Associated Infection Prevalence Survey 2006: overview of the results.

2. Bruce J, Russell EM, Millinson J, Krukowksi ZH: The measurement and monitoring of surgical adverse events.

3. Astagneau P, Rioux C, Golliot F, Br $\tilde{A}^{1} / 4$ cker G, INCISO Network Study Group: Morbidity and mortality associated with surgical site infections: results from the 1997-1999 INCISO surveillance.

4. Bayat A, McGrouther DA, Ferguson MW: Skin scarring. British Medical Journal 2003, 326:88-92. Coelle R, Charlett A, Wilson J, Ward V, Pearson A, Borriello P: Adverse impact of surgical site infections in English hospitals.

5. Plowman R, Graves N, Griffin MA, Roberts JA, Swan AV, Cookson B, Taylor L: The rate and cost of hospital-acquired infections occurring in patients admitted to selected specialities of a district general hospital in England and the national burden imposed.

6. National Institute for Health and Clinical Excellence: Surgical site infection. 2008.

7. Webster $\mathrm{J}$, Alghamdi A: Use of plastic adhesive drapes during surgery for preventing surgical site infection.

8. 8. Nichols RL, Smith JW, Garcia RY, Waterman RS, Holmes JW. Current practices of preoperative bowel preparation among North American colorectal surgeons. Clin Infect

9. 9. Zmora O, Wexner SD, Hajjar L, Park T, Efron JE, Nogueras JJ, Weiss EG. Trends in preparation for colorectal surgery: survey of the members of the American Society of Colon and Rectal Surgeons. Am Surg.

10. Rahman MH. And Anson J (2004). Peri-operative anti-bacterial The Pharm J. 272:743-745.

11. Mangram AJ, Horan TC, Pearson ML, Silver LC, Jarvis WR (1999). Guideline for prevention of surgical 
site infection. Hospital Infection Control Practices Advisory Committee. Infect Cont Hosp Epidemiology. 20: 250-278.

12. Gedebou M, Habte-Gabr E, Kronvall G, Yoseph S(1988). Hospital-acquired infections among obstetric and gynecological patients at TikurAnbessa Hospital, Addis Ababa.J Hosp Infect. 11:50-59.

13. Kotisso B, Aseffa A (1998). Surgical wound infection in a teaching hospital in Ethiopia. Afr Med J. 75: 402405.

14. http://www.who.int/entity/patientsafety/safesurgery/tools_resources/SSSL_Checklist_finalJun08.pdf

15. Garner J, Jarvis W, Emori T, Horan T, Hughes J (1996). CDC definitions of Nosocomial infection. APIC infection control and applied epidemiology, principles and practice. St. Louis \& Mosby. A1 - A20.

16. Michalopoulos A, Sparos L (2003). Post-operative wound infections. Nurs Stand. 17: 53-60.

17. Ryan KJ (1994). Skin and wound infections. In: RyanKJ, eds. Sherris, Medical Microbiology: an introduction to infectious diseases.3rded. Appleton \& Lange. 731-736.

18. Weinstein RA (2005). Hospital acquired infections. In: Harrison, principles of Internal medicine. McGraw-Hill Companies, Inc. 1: 775-778.

19. Kollef MH, Sharpless L, Vlasnik J, Pasque C, MurphyD, Fraser VJ(1997). The impact of Nosocomial infections on patient outcomes following cardiac surgery. Chest. 112: 666-675.

20. Habte-Gabr E, Gedebou M, Kronvall G (1988). Hospital-acquired infections among surgical patients in Tikur Anbessa Hospital, Addis Ababa, Ethiopia. Am J Infection Control. 16:7-13

21. Zotti CM, Messori Ioli G, Charrier L, Arditi G, Argentero PA, Biglino A, Farina EC, Moiraghi Ruggenini A, Reale R, Romagnoli S, Serra R, Soranzo ML, Valpreda M

22. 542004). Hospital Coordinator Group.Hospital-acquired infection in Italy: a region wide prevalence study. J Hosp Infect. 56:142-149.

\section{Annex-II: QUESTIONNAIRE}

Questionnaires to investigate the prevalence of surgical site infections among

Patients admitted to WSTR Hospital, southern, Ethiopia.

\section{Patient Identification}

1. Patient full name

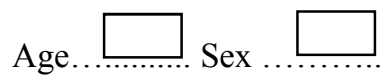

2. Address ...Card number.

Rural
3. Ward:
A) surgical
B) Gyn/Oby

Urban

4. Reason for admission/diagnosis of admission before surgery. A) Obstetric

5. The duration operation taken.

A) Less than 30 minutes

C) Surgical

B) Gynecologic

B) 30-60 minutes

C) 60-90 minutes

D) $>90$ minutes

6. Type of surgery. A) Elective

B) Emergency

7. Type of anesthesia given A) General B) Regional

8. The time of postoperative wound infection diagnosed.
A) Within two days post surgery
B) 3-4 day post operation
C) $5^{\text {th }}$ and more days after surgery
D) at home after discharge

9. Antibiotic prophylaxis given 1.Yes

10 . Duration of hospital stay after surgery.
A) 1-4 day
C) 9-14 day
B) 5-8 day
D) More than two week 